\title{
Sensorless Speed Control of Permanent Magnet Synchronous Motors by Neural Network Algorithm
}

\author{
Ming-Shyan Wang, Ika Noer Syamsiana, and Feng-Chi Lin \\ Department of Electrical Engineering, Southern Taiwan University of Science and Technology, 1 Nan-Tai Street, Yung Kang District, \\ Tainan City 710, Taiwan \\ Correspondence should be addressed to Ming-Shyan Wang; mswang@mail.stust.edu.tw
}

Received 20 August 2014; Accepted 8 September 2014; Published 25 September 2014

Academic Editor: Stephen D. Prior

Copyright (C) 2014 Ming-Shyan Wang et al. This is an open access article distributed under the Creative Commons Attribution License, which permits unrestricted use, distribution, and reproduction in any medium, provided the original work is properly cited.

\begin{abstract}
The sliding mode control has the merits with respect to the variation of the disturbance and robustness. In this paper, the sensorless sliding-mode observer with least mean squared error approach for permanent magnet synchronous motor (PMSM) to detect the rotor position by counter electromotive force and then compute motor speed is designed and implemented. In addition, the neural network control is also used to compensate the PI gain tuning to increase the speed accuracy without regarding the errors of the current measurement and motor noise. In this paper, a digital signal processor TMS320F2812 utilizes its high-speed ADC module to get current feedback information and thus to estimate the rotor position and takes advantage of the built-in modules to achieve SVPWM current control so that the senseless speed control will be accomplished. The correctness and effectiveness of the proposed control system will be verified from the experimental results.
\end{abstract}

\section{Introduction}

Nowadays, the permanent magnet synchronous motor (PMSM) is more widely applied than before in the servo control systems. For servo control systems, their excellent performance comes from using position sensors for feedback control. However, the disadvantages of shaft sensors limit the applications, such as system cost increasing, motor size, and reliability decreasing in applications such as air conditioner compressors, where the environment is highly humid and hot. As a result, extensive research has been conducted on overcoming these difficulties by eliminating the position sensors in servomotor systems [1].

Two kinds of sensorless control methods are popularly used in servo control systems, fundamental model based method and saliency based method. Fundamental model based method uses observers, such as back electromotive force (EMF) observer and flux linkage observer, to estimate the rotor position. Meanwhile, the saliency based method consists of continuous signal injection and transient voltage vector injection [2]. Some authors proposed to estimate speed and position of PMSM by back-EMF or flux linkage but it is hard at low speed operation and standstill because back EMF amplitude is approaching zero. Other references compared several methods and recommended continuous signal injection method for low operating speed because of its simple hardware configuration. However, the torque ripple and acoustic noise by continuous signal injection are larger than other methods.

A flux linkage estimation method [3] is developed by first measuring the stator line-to-line voltages and stator phase current to obtain the back EMF space vector. This vector in turn is used to yield the angle of the flux linkage vector. However, it is affected by integrator drift in low speed and its accuracy is highly sensitive to parameter variation. Another observer based method [4] is presented that removes the dependency on mechanical parameters; however there is still the need for an electrical model of the machine. The tracking control problem is addressed for a sensorless PMSM with unknown constant load torque. Assuming that only stator currents and voltages are available for feedback, a novel sixth order nonlinear adaptive control algorithm is 
designed for the PMSM [5]. However, the proposed control algorithm is tested just by simulation. A high-speed slidingmode observer [6] is proposed for PMSM, which estimates the rotor position and the angular velocity from the back EMF. Carrier-signal-injection-based control methods [7] are proposed for sensorless control. Fundamental pulse width modulation excitation is used to improve sensorless control of a permanent magnet machine [8]. No additional signal injection or separate test vectors are required. However, modification is needed when narrow PWM voltage vectors occur.

Recently, artificial neural networks (ANNs) have attracted much attention to their possible use in a wide range of engineering applications like power electronics or motor drives [9-15]. The use of ANNs is motivated by their useful features, like having a parallel distributed architecture, being able to identify nonlinear system dynamics, and having the ability to learn, generalize, and adapt. All of these features justify the use of ANNs for motor drive applications, including sensorless control.

This paper presents a neural network based approach to the sensorless control of the PMSM. The basic premise of the method is that an ANN provides a very efficient mapping structure for the nonlinear PMSM. By measuring the phase currents and applying them as inputs to the estimator by least mean squares, the rotor angle is estimated, thereby facilitating the elimination of the rotor position sensor. An NN with back propagation algorithm is considered to compensate the PI gains for speed control.

The paper is organized as follows for further discussion. Section 2 introduces system description including PMSM modeling, neural network with LMS compensation for rotor angle estimation, and speed control by ANN. Section 3 consists of simulation by Matlab/Simulink and experiments. Finally, a conclusion is given in Section 4.

\section{Servo System Design}

There are three parts for the proposed servo control system design, PMSM modeling, sliding-mode observer (SMO) with LMS approach, and PI speed control compensated by neural networks.

2.1. PMSM Modeling. By Park and Clarke transformations, the voltage equations of PMSM from the stationary a-b-c frame to the $\alpha-\beta$ frame and the rotating $d-q$ frame will be given as [9-15]

$$
\begin{aligned}
& {\left[\begin{array}{l}
v_{\alpha} \\
v_{\beta}
\end{array}\right]=\left[\begin{array}{cc}
R_{s}+\frac{d}{d t} L_{s} & 0 \\
0 & R_{s}+\frac{d}{d t} L_{s}
\end{array}\right]\left[\begin{array}{l}
i_{\alpha} \\
i_{\beta}
\end{array}\right]+\left[\begin{array}{c}
e_{\alpha} \\
e_{\beta}
\end{array}\right],} \\
& {\left[\begin{array}{l}
v_{d} \\
v_{q}
\end{array}\right]=\left[\begin{array}{cc}
R_{s}+\frac{d}{d t} L_{s} & -\omega_{r} L_{s} \\
\omega_{r} L_{s} & R_{s}+\frac{d}{d t} L_{s}
\end{array}\right]\left[\begin{array}{c}
i_{d} \\
i_{q}
\end{array}\right]+\left[\begin{array}{c}
0 \\
\omega_{r} \lambda_{f}
\end{array}\right],}
\end{aligned}
$$

where $v_{d}, v_{q}$ are $d$ - and $q$-axis voltages; $i_{d}, i_{q}$ are $d$ - and $q$-axis currents; $\lambda_{f}$ is flux linkage due to the permanent magnets; $\omega_{r}$ is the electric speed; and $R_{s}$ and $L_{s}$ are the resistance and inductance. The $\alpha$-and $\beta$-axis back EMFs are given as

$$
\begin{gathered}
e_{\alpha}=-\lambda_{f} \omega_{r} \sin \theta, \\
e_{\beta}=\lambda_{f} \omega_{r} \cos \theta .
\end{gathered}
$$

The use of the Park transformation implies using the rotor position. However, the actual rotor position is not known in a sensorless application and needs to be estimated. Figure 1 shows the block diagram of sensorless PMSM control system, which will be simulated by Matlab/Simulink and experimented to verify the design.

2.2. Sliding-Mode Observer with LMS Approach. Control systems with sliding-mode control (SMC) may have better performance of smaller settling time, less or no overshoot, and faster tracking ability. In addition, sliding-mode observer (SMO) can provide information of rotor position and speed estimation. The dynamic equations of SMO are given as follows:

$$
\begin{aligned}
& \frac{d}{d t} \widehat{i}_{\alpha}=-\frac{R_{s}}{L_{s}} \widehat{i}_{\alpha}+\frac{1}{L_{s}} v_{\alpha}-\frac{1}{L_{s}} k *\left(\widehat{i}_{\alpha}-i_{\alpha}\right), \\
& \frac{d}{d t} \widehat{i}_{\beta}=-\frac{R_{s}}{L_{s}} \hat{i}_{\beta}+\frac{1}{L_{s}} v_{\beta}-\frac{1}{L_{s}} k *\left(\hat{i}_{\beta}-i_{\beta}\right),
\end{aligned}
$$

where $\hat{i}_{\alpha}$ and $\hat{i}_{\beta}$ are the estimated variables of $i_{\alpha}$ and $i_{\beta}$ and $k$ is observer gain. The sliding vector for the system is

$$
S_{n}=\left[s_{\alpha}, s_{\beta}\right]^{T}=\left[\hat{i}_{\alpha}-i_{\alpha}, \hat{i}_{\beta}-i_{\beta}\right]^{T}
$$

and the defined Lyapunov function is

$$
V=\frac{1}{2} S_{n}^{T} S_{n}=\frac{1}{2}\left(s_{\alpha}^{2}+s_{\beta}^{2}\right) .
$$

The observer gain $k$ will be designed to satisfy Lyapunov's stability theorem, $\dot{V}<0$, as the system trajectory approaches to the sliding hyperplane, $S_{n}=0$. As a result, we have

$$
\begin{aligned}
& \widehat{e}_{\alpha}=k * \bar{i}_{\alpha}, \\
& \widehat{e}_{\beta}=k * \bar{i}_{\beta}
\end{aligned}
$$

and the estimated rotor angle is

$$
\widehat{\theta}=-\tan ^{-1}\left(\frac{\widehat{e}_{\alpha}}{\widehat{e}_{\beta}}\right) .
$$

In order to compensate the rotor position estimation error due to the process of motor speed tracking and noise, an adaptive linear element neural network (NN) structure shown in Figure 2 with least mean square approach is adopted. Artificial NNs are similar to biological NNs in the sense that they are based on the same principle of operation based on highly parallel structure and acquiring knowledge through a learning process [16]. The building blocks of an ANN are simple computational nodes, called 


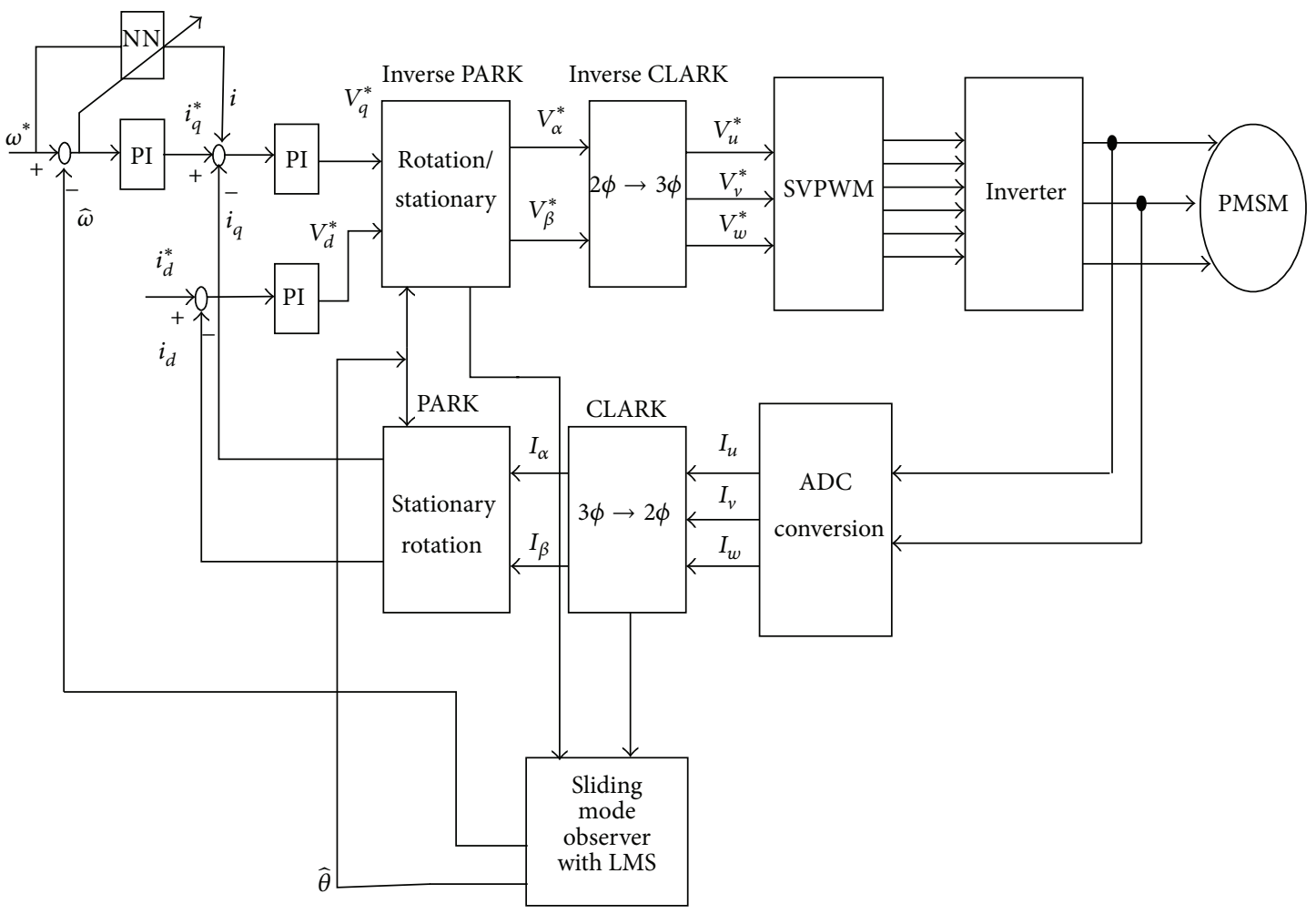

FIGURE 1: Block diagram of the proposed control system.

neurons. They are connected into a network structure by weighted connections, much like the synaptic connections in the human brain. Although the components of an NN are simple and few, the structure and type of these networks vary greatly, determined by the ever increasing interest in this research field.

In Figure 2, $x_{1}, x_{2}, \ldots, x_{n}$ are input variables, $w_{k 1}, w_{k 2}, \ldots, w_{k n}$ are weights, $b_{k}$ is the bias, $\Delta \bar{e}=$ $\left(e_{1}+e_{2}+e_{3}+\cdots+e_{n}\right) / n$ is averaged error, and $d(k)$ is the reference angle from the speed command, respectively. If the estimated error at time instant $k$ is $e(k)$, by LMS approach, we have the follow equations [9-16]:

$$
\begin{gathered}
\frac{\partial e^{2}(k)}{\partial w_{1, j}}=2 e(k) \frac{\partial e(k)}{\partial w_{1, j}} \quad j=1,2, \ldots, n, \\
\frac{\partial e^{2}(k)}{\partial b_{k}}=2 e(k) \frac{\partial e(k)}{\partial b_{k}}, \\
w(k+1)-w(k)=\Delta w=2 \alpha e(k) x_{n}(k), \\
b(k+1)-b(k)=\Delta b=2 \alpha e(k), \\
w(k+1)=w(k)+2 \alpha e(k) x_{n}(k), \\
b(k+1)=b(k)+2 \alpha e(k),
\end{gathered}
$$

where $\alpha$ is the learning rate.

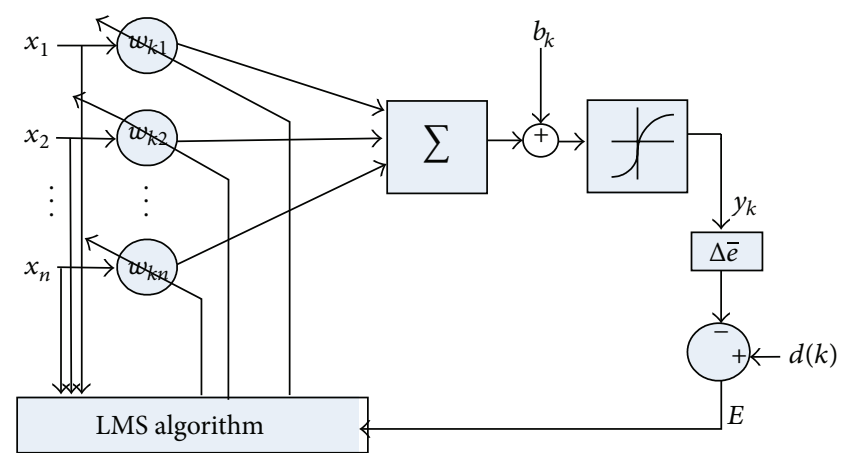

FIGURE 2: Structure of adaptive linear element neural network.

2.3. PI Speed Control Compensated by Neural Networks. The proportional-integral (PI) control is first considered in the system,

$$
G_{s}(s)=K_{s p}+\frac{K_{s i}}{s},
$$

where $K_{s p}$ and $K_{s i}$ are the proportional gain and integral gain, respectively. PI controller is widely used in the industrial applications. However, it cannot cope with the load variation or parameter variation well. In the paper, the ANN with back propagation algorithm is utilized to compensate the PI control quantity as shown in Figure 1. 


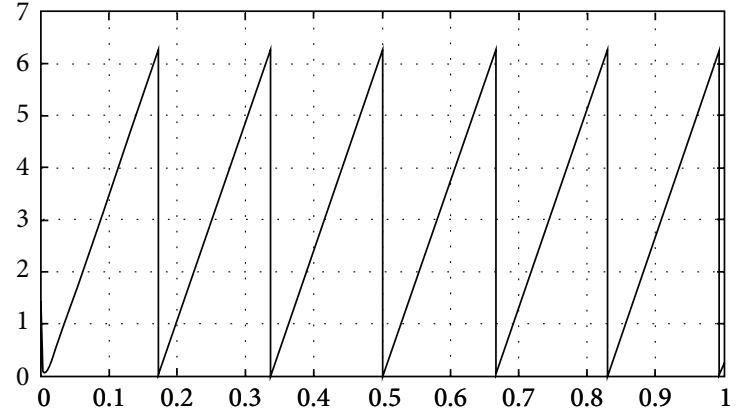

Figure 3: The estimated rotor angle with SMO at speed of $100 \mathrm{rpm}$ by simulation.

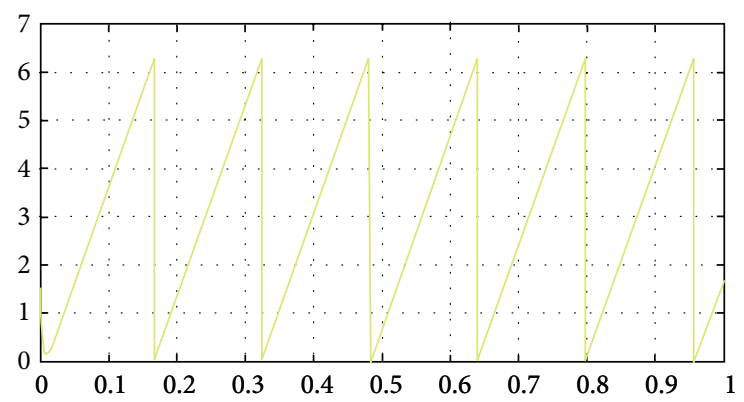

FIGURE 4: The estimated rotor angle with SMO and LMS at speed of $100 \mathrm{rpm}$ by simulation. as

The output of the $j$ th neuron at the $n$th layer is calculated

$$
\begin{gathered}
y_{j}^{n}=f\left(\operatorname{net}_{j}^{n}\right), \\
\operatorname{net}_{j}^{n}=\sum_{i} w_{j i}^{n} y_{i}^{n-1}+b_{j}^{n} .
\end{gathered}
$$

The error function is defined as

$$
E=\frac{1}{2} \sum_{k}\left(d_{k}-y_{k}\right)^{2} .
$$

The conjugated gradient method is considered to find the minimum value of the error function (11).

\section{Simulation and Experimental Results}

The system simulation is programmed by Matlab/Simulink. The parameters of PMSM 8CB75 are listed in Table 1. After training, the chosen topology that gives good performance with minimal resources is a 2-hidden-neuron structure for the speed estimating neural network. The activation functions in the hidden layers of the networks are hyperbolic tangent sigmoid functions and those of the output layer are purely linear transfer functions. The values of these weights are given as input layer to hidden layer weights: $\{837.4172,-126.4659\}$, hidden layer to output layer weights: $\{-0.614,0.6713\}$, hidden neurons' thresholds: $\{12.5996,8.3947\}$, and output neuron's threshold: 0.6560 . The final mean squared error of $3.83267 * 10^{-17}$ is reached

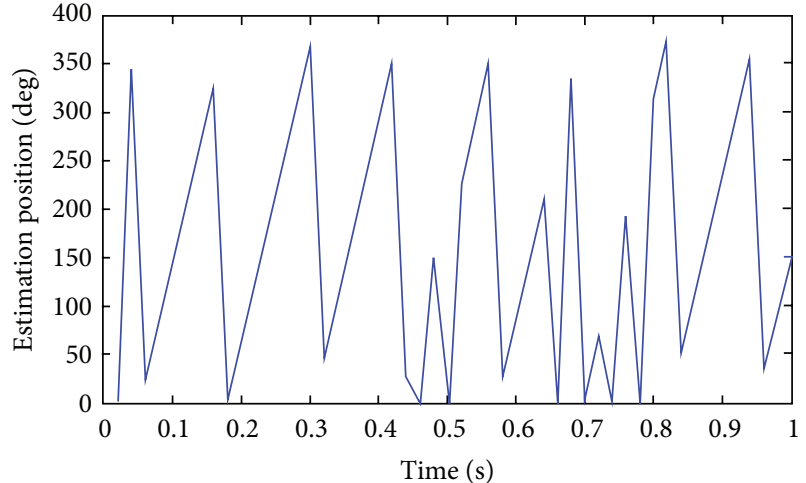

FIGURE 5: The real estimated rotor angle with SMO at speed of $100 \mathrm{rpm}$.

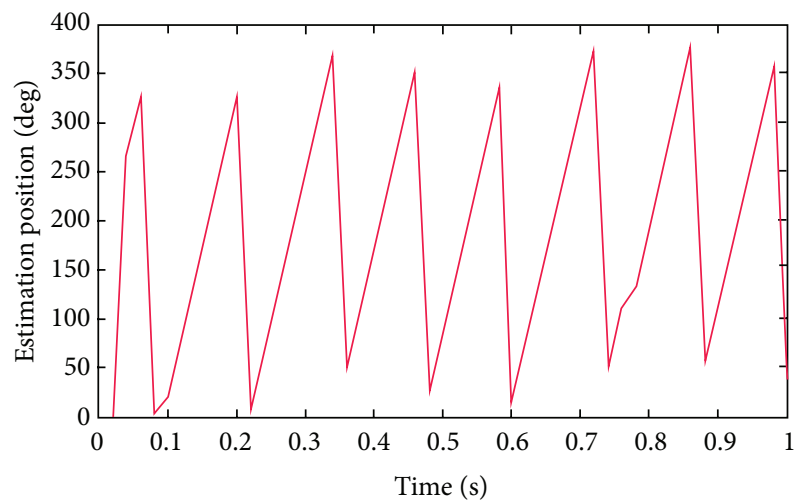

FIgURE 6: The real estimated rotor angle with SMO and LMS at speed of $100 \mathrm{rpm}$.

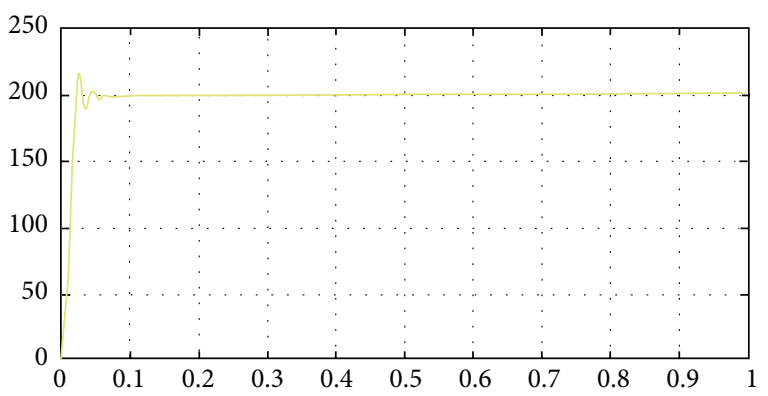

FIGURE 7: The speed response of $200 \mathrm{rpm}$ without compensation by simulation.

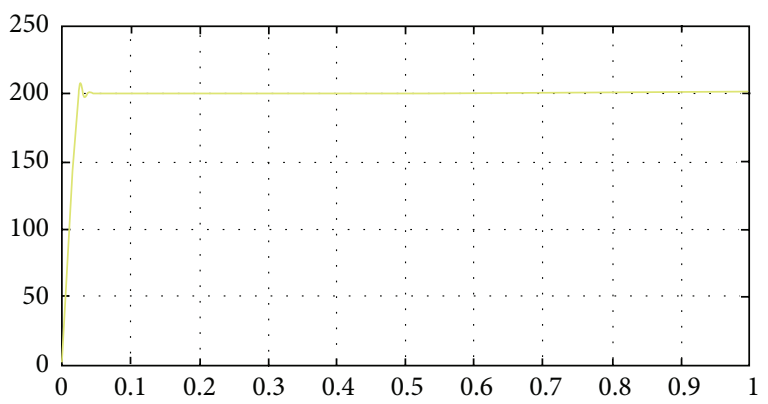

FIGURE 8: The speed response of $200 \mathrm{rpm}$ with NN compensation by simulation. 


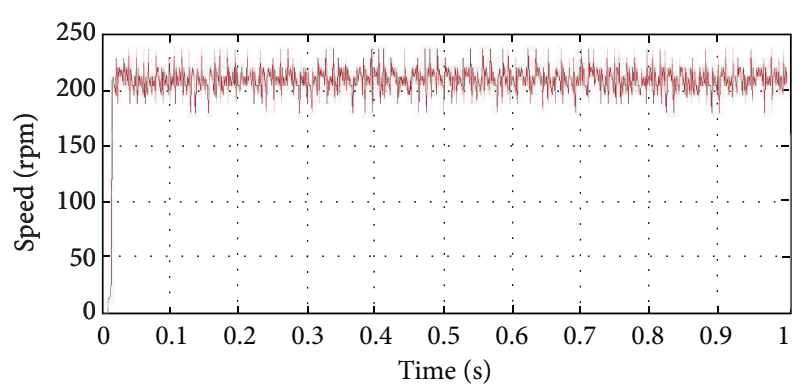

(a)

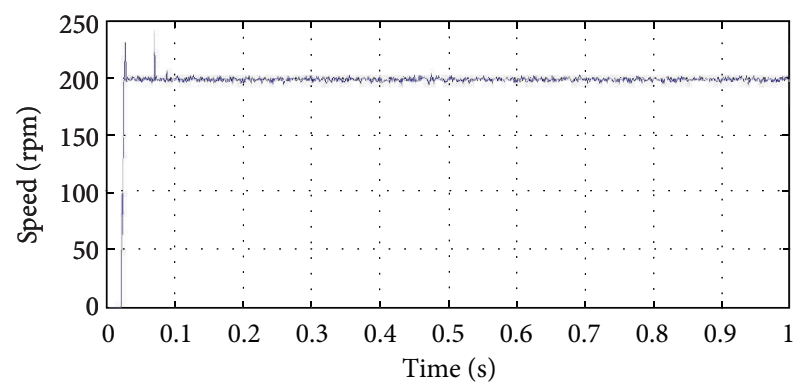

(b)

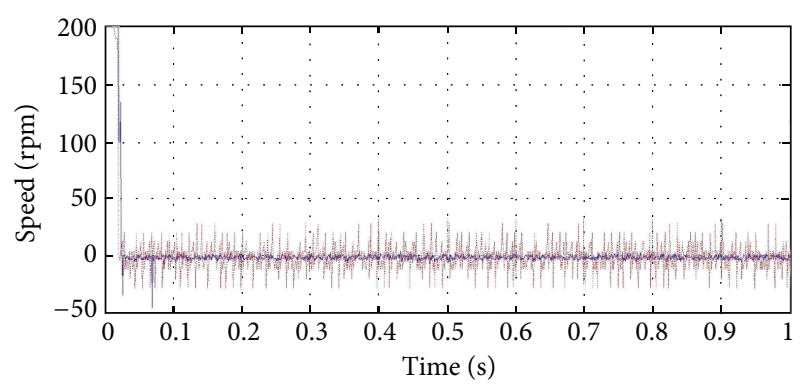

(c)

Figure 9: The no-load speed responses of $200 \mathrm{rpm}$ without (a) and with NN compensation (b) and the speed errors (c) (blue for no compensation).

after 20 training epochs for the neural networks. The gain constants of PI control are $K_{s p}=1.2$ and $K_{s i}=1.5$, respectively. These parameters are applied to the simulation and experimentation.

Figures 3 and 4 display the rotor angle estimation with SMO and with SMO plus LMS at the motor speed of $100 \mathrm{rpm}$, respectively. It is easy to find the accuracy of little difference by simulation. However, for experimentation, the great difference between the estimated values can be shown in Figures 5 and 6 . One of the reasons is lack of estimation of initial rotor position, which is our next research topic. As a result, there are no complete triangle position waveforms from zero degree to 360 degrees in the figures. In addition, the step speed responses of $200 \mathrm{rpm}$ without and with NN compensation are depicted in Figures 7 and 8. The latter has better performance of less overshoot and settling time. For experimentation, the no-load speed responses of $200 \mathrm{rpm}$ without (a) and with NN compensation (b) and the speed errors (c) (blue for no compensation) are displayed

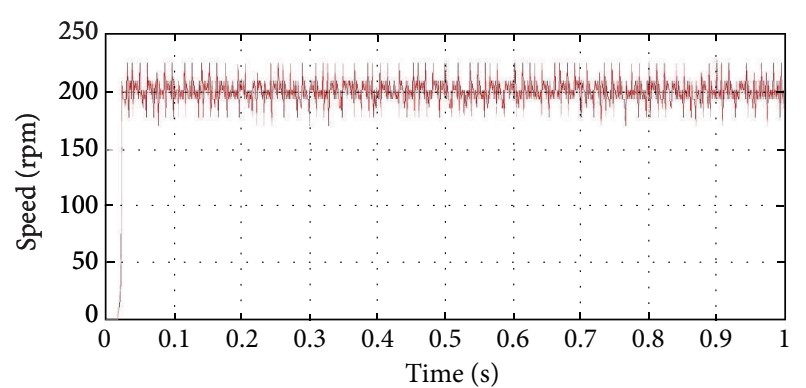

(a)

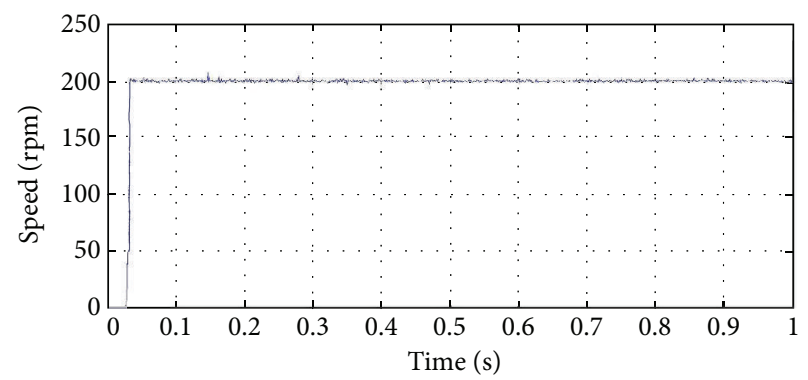

(b)

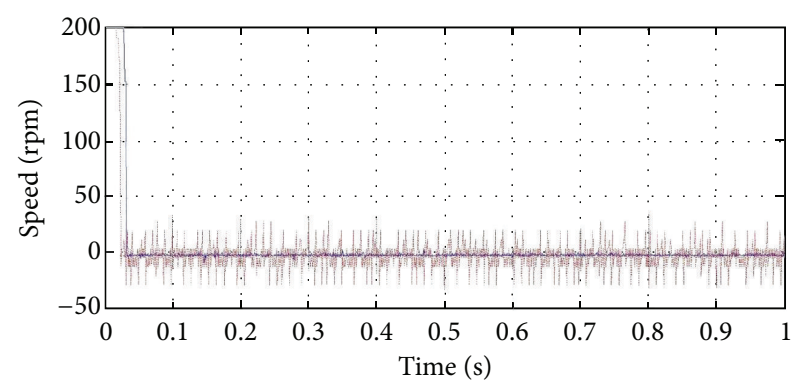

(c)

FIGURE 10: The speed responses of $200 \mathrm{rpm}$ without (a) and with NN compensation (b) and the speed errors (c) (blue for no compensation) under loading of $1 \mathrm{~kg}$ disc.

in Figure 9. Simultaneously, the step speed responses of $200 \mathrm{rpm}$ with $1 \mathrm{~kg}$ disc load are shown in Figure 10. The speed responses without compensation display both the computing errors and the noise during motor rotation. The one by $\mathrm{NN}$ control has almost no overshoot, very short settling time, and zero steady-state error. The speed step responses of 100-150$100 \mathrm{rpm}$ without (a) and with NN compensation (b) under loading of $1 \mathrm{~kg}$ disc are shown in Figure 11. The effectiveness of the proposed algorithm shows more clearly.

\section{Conclusions}

This paper proposes a sensorless control system for PMSM by presenting an approach based on neural networks to compensate both the estimated position error and PI control gains. The suggested method is useful for applications to reduce cost. The simulation and experimental results show that the controlled system is capable of estimating rotor 


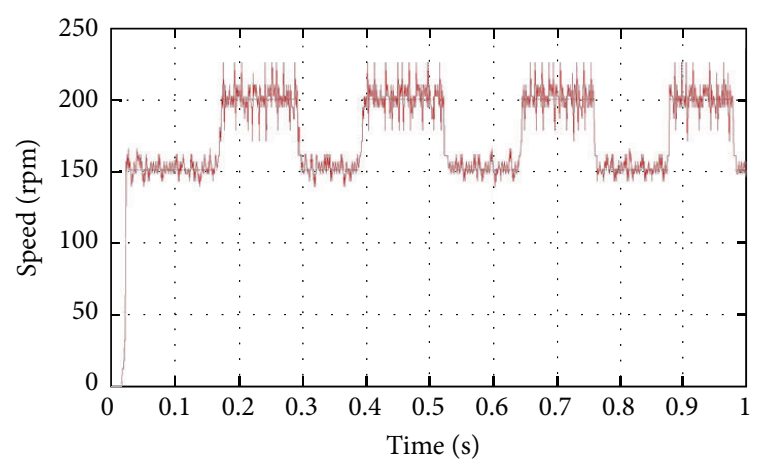

(a)

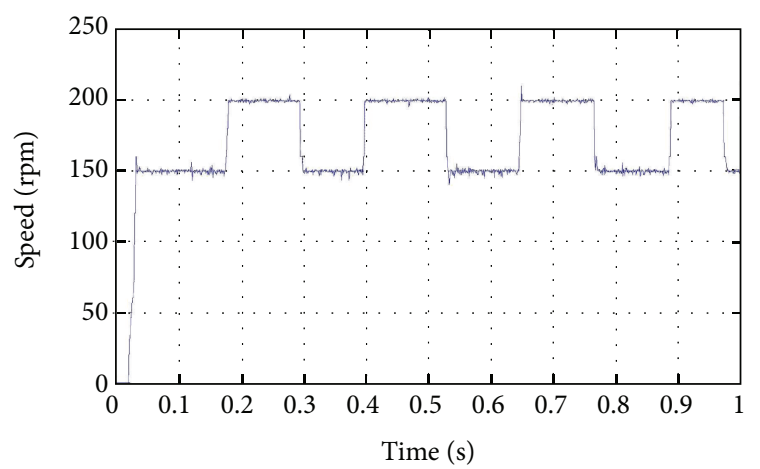

(b)

FIGURE 11: The speed responses of 100-150-100 rpm without (a) and with $\mathrm{NN}$ compensation (b) under loading of $1 \mathrm{~kg}$ disc.

TABLE 1: Parameters of PMSM Sinano 8CB75.

\begin{tabular}{lcc}
\hline Parameters & Unit & Value \\
\hline$P$ & $\mathrm{~W}$ & 750 \\
$V$ & $\mathrm{~V}$ & 149.4 \\
$T$ & $\mathrm{~N} \cdot \mathrm{m}$ & 2.931 \\
$I$ & $\mathrm{~A}$ & 3.4 \\
$N$ & $\mathrm{Rpm}$ & 3000 \\
$K$ & $\mathrm{~N} \cdot \mathrm{m} / \mathrm{A}$ & 0.776 \\
$J$ & $\mathrm{Kg} \cdot \mathrm{cm}^{2}$ & 2.449 \\
$R$ & $\Omega$ & 3.27 \\
$L$ & $\mathrm{mH}$ & 10.2 \\
\hline
\end{tabular}

angle and motor speed within acceptable limits for many applications.

\section{Conflict of Interests}

The authors declare that there is no conflict of interests regarding the publication of this paper.

\section{Acknowledgments}

The authors would like to express their appreciation to Ministry of Science and Technology, Taiwan, under Contract no. NSC 100-2632-E-218-001-MY3 and MOST 103-2221-E218-033- for their financial support.

\section{References}

[1] B. Nahid-Mobarakeh, F. Meibody-Tabar, and F.-M. Sargos, "Back EMF estimation-based sensorless control of PMSM: robustness with respect to measurement errors and inverter irregularities," IEEE Transactions on Industry Applications, vol. 43, no. 2, pp. 485-494, 2007.

[2] J. M. Liu and Z. Q. Zhu, "Novel sensorless control strategy with injection of high frequency pulsating carrier signal into stationary reference frame," IEEE Transactions on Industry Applications, vol. 50, no. 4, pp. 2574-2583, 2013.

[3] R. Wu and G. R. Slemon, "A permanent magnet motor drive without a shaft sensor," IEEE Transactions on Industry Applications, vol. 27, no. 5, pp. 1005-1011, 1991.

[4] T. D. Batzel and K. Y. Lee, "Starting method for sensorless operation of slotless permanent magnet synchronous machines," in Proceedings of the IEEE Power Engineering Society Summer Meeting, pp. 1243-1247, Alberta, Canada, 1999.

[5] P. Tomei and C. M. Verrelli, "Observer-based speed tracking control for sensorless permanent magnet synchronous motors with unknown load torque," IEEE Transactions on Automatic Control, vol. 56, no. 6, pp. 1484-1488, 2011.

[6] H. Kim, J. Son, and J. Lee, "A high-speed sliding-mode observer for the sensorless speed control of a PMSM," IEEE Transactions on Industrial Electronics, vol. 58, no. 9, pp. 4069-4077, 2011.

[7] Z. Q. Zhu and L. M. Gong, "Investigation of effectiveness of sensorless operation in carrier-signal-injection-based sensorlesscontrol methods," IEEE Transactions on Industrial Electronics, vol. 58, no. 8, pp. 3431-3439, 2011.

[8] Y. Hua, "Improved sensorless control of a permanent magnet machine using fundamental pulse width modulation excitation," IET Electric Power Applications, vol. 5, no. 4, pp. 359-370, 2011.

[9] T. D. Batzel and K. Y. Lee, "An approach to sensorless operation of the permanent-magnet synchronous motor using diagonally recurrent neural networks," IEEE Transactions on Energy Conversion, vol. 18, no. 1, pp. 100-106, 2003.

[10] F. F. M. El-Sousy, "Hybrid $H_{\infty}$-based wavelet-neural-network tracking control for permanent-magnet synchronous motor servo drives," IEEE Transactions on Industrial Electronics, vol. 57, no. 9, pp. 3157-3166, 2010.

[11] H.-J. Guo, S. Sagawa, T. Watanabe, and O. Ichinokura, "Sensorless driving method of permanent-magnet synchronous motors based on neural networks,' IEEE Transactions on Magnetics, vol. 39, no. 5, pp. 3247-3249, 2003.

[12] F.-J. Lin, L.-T. Teng, and H. Chu, "Modified Elman neural network controller with improved particle swarm optimisation for linear synchronous motor drive," IET Electric Power Applications, vol. 2, no. 3, pp. 201-214, 2008.

[13] J. Yang, Y. Wu, Y. Yu, and W. Zhao, "Permanent magnet synchronous motor control based on retina neural network," in Proceedings of the International Conference on E-Product E-Service and E-Entertainment (ICEEE '10), Henan, China, November 2010.

[14] H. Li, J. Wang, S. S. Gu, and T. Yang, "A neural-networkbased adaptive estimator of rotor position and speed for permanent magnet synchronous motor," in Proceedings of the 5th International Electrical Machines and Systems (ICEMS '01), vol. 2, pp. 735-738, Shenyang, China, August 2001. 
[15] Y. A.-R. I. Mohamed, "Design and implementation of a robust current-control scheme for a PMSM vector drive with a simple adaptive disturbance observer," IEEE Transactions on Industrial Electronics, vol. 54, no. 4, pp. 1981-1988, 2007.

[16] L. H. Tsoukalas and R. E. Uhrig, Fuzzy and Neural Approaches in Engineering, John Wiley \& Sons, New York, NY, USA, 1997. 


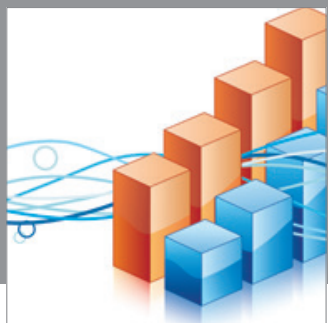

Advances in

Operations Research

mansans

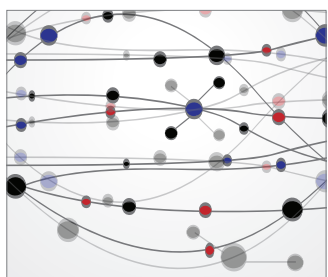

The Scientific World Journal
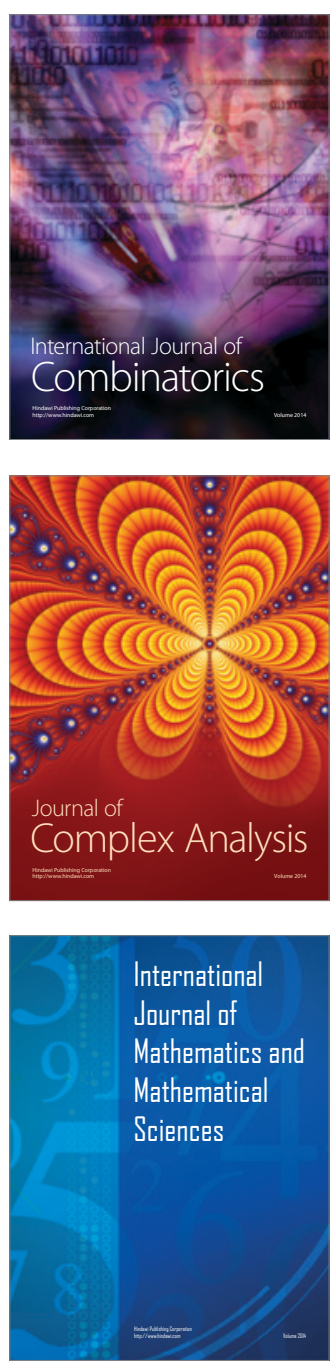
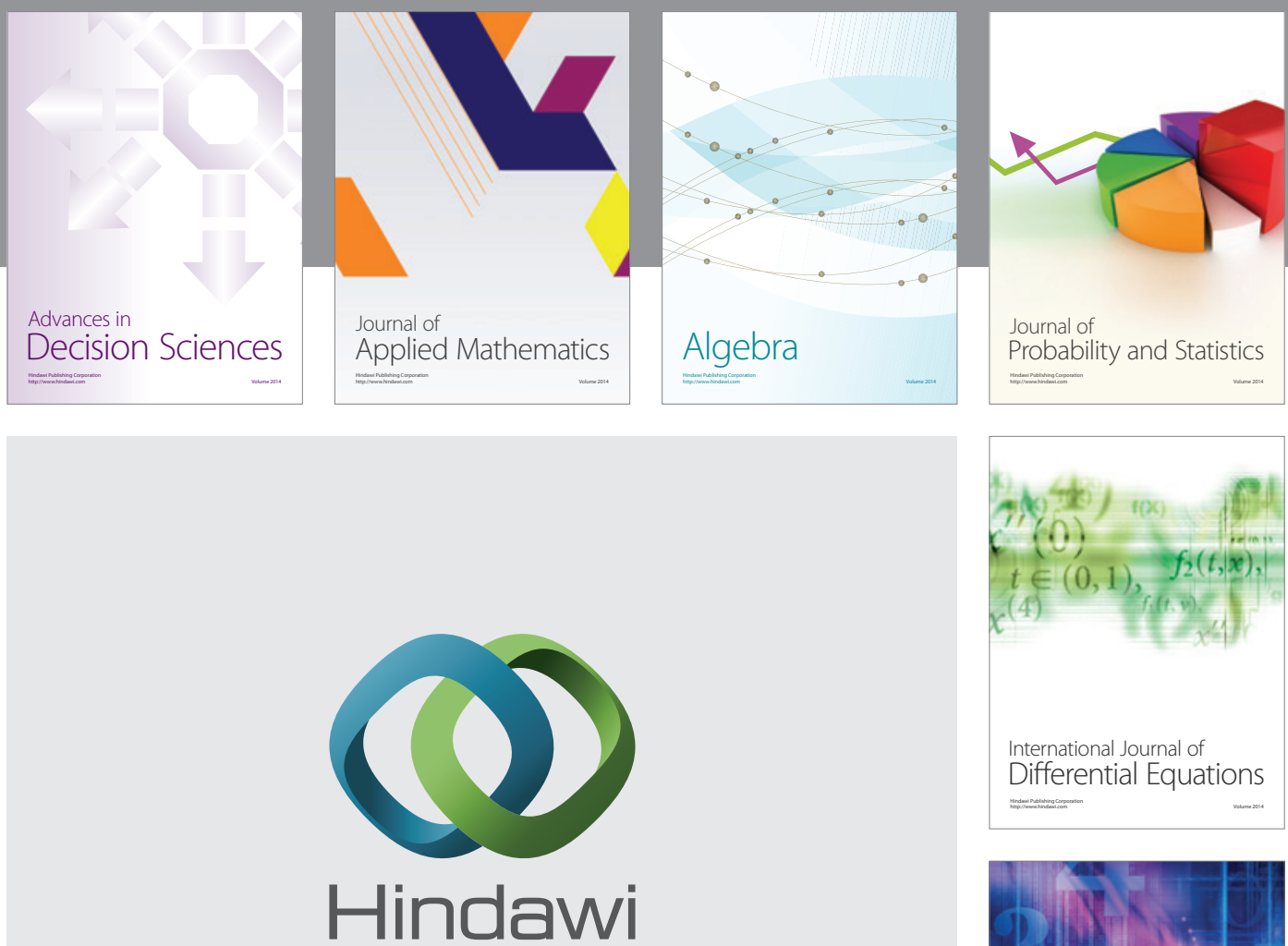

Submit your manuscripts at http://www.hindawi.com
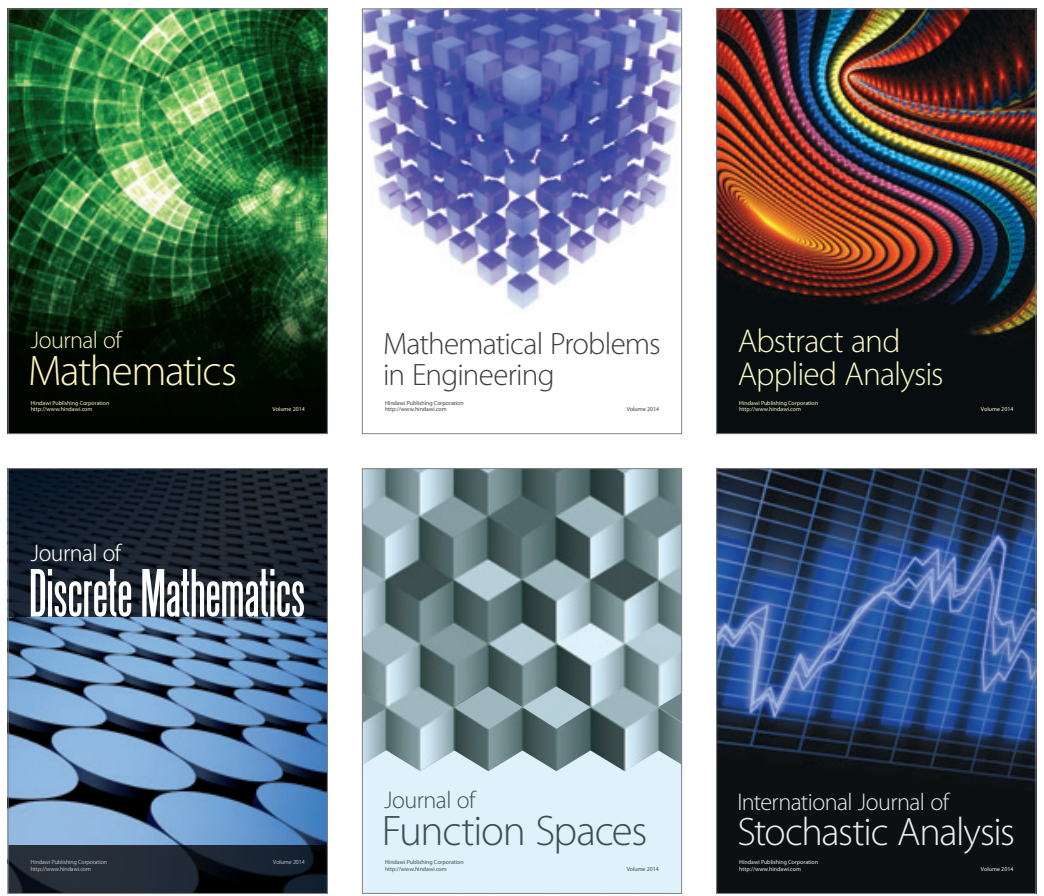

Journal of

Function Spaces

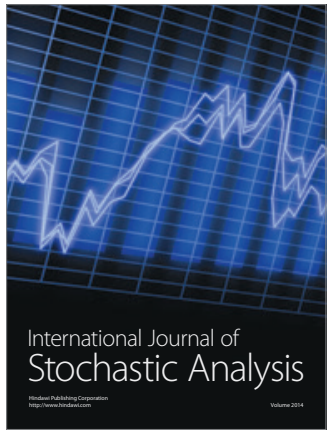

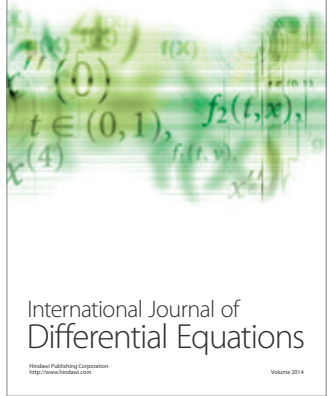
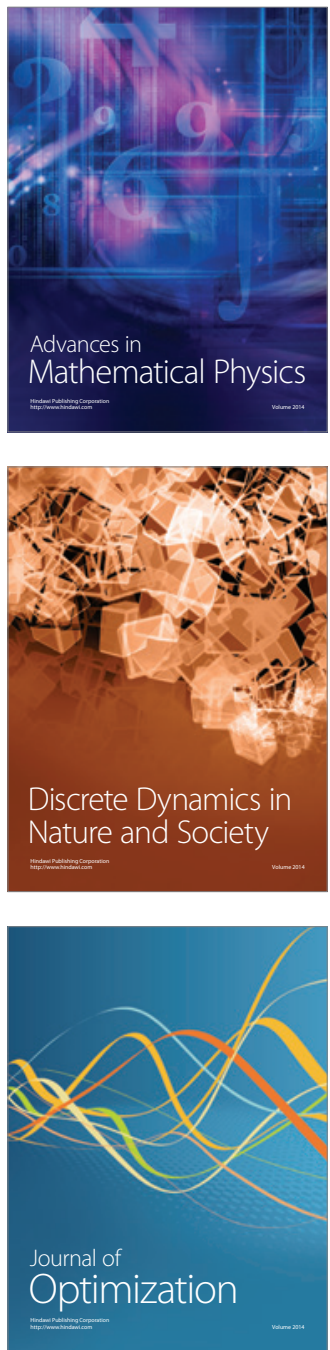